the two sections of the book is a short self-assessment section of questions and answers. This format works well. Not only are the basic principles emphasised, but their importance in the clinical context becomes apparent in the second part of the book.

The preface to the first edition clearly identified undergraduate students as the target market for this book. That preface has now been omitted and replaced by a new one, which directs this new edition at those whose practice as clinicians, scientists, counsellors, and teachers requires an understanding of modern medical genetics. To this end, new chapters have been added dealing with the genetics of common disorders and cancer genetics. The text generally has been updated to take account of advances since the last edition. Some figures have been replaced and new figures have been added. Tables are now printed in a separate colour, as are key subheadings within each chapter. All of these changes underline the continuing thought and effort on the authors' part which this new edition represents. These efforts have produced a useful and concise basic textbook, which is well bound, attractively presented, and enjoys the advantage of an index.

The range of topics covered is broad and should give interested readers a flavour of the clinical situations in which a geneticist may usefully contribute. No book is perfect, however, and the specific problem with this one is that the quality is quite variable from one chapter to the next. The contributions on chromosomes, chromosomal aberrations, and cancer genetics are excellent, with a clear text complementing exceptionally good diagrams. In contrast, the same clarity is not apparent in the chapter on population genetics, which seems destined to confuse readers. The greatest disappointment is the chapter dealing with nucleic acid structure and function, in which the combination of a loose text and poor labelling of some new figures makes frustrating reading. These fundamental areas surely deserve careful revision in the next edition to bring them into line with the high standard which the book generally sets. Notwithstanding these reservations this is a book to be recommended. It will serve students well and, although unlikely to command pride of place on the clinical geneticist's bookshelf, may be a useful basic source of reference when memory fails.

\section{WILLIAM REARDON}

Genes and Cancer. Ed Desmond Carney, Karol Sikora. (Pp 348; £24.95.) Chichester: John Wiley. 1990.

This is an excellent compilation of short reviews covering most current research into the molecular biology of cancer. In some 300 pages it provides an insight into the whole field from the biochemistry of individual oncogenes to the potential applications of molecular biology to cancer therapy. Established principles are clearly explained, and there is no lack of up to the minute data. A feature of the book which should be particularly useful for those not active at the bench is the inclusion of succinct overviews of technical procedures. The layout of the book in general follows a logical sequence, although it is not clear why chapters on mitochondria and inherited cancer syndromes should have been included in the section on transcriptional control! There are only two notable shortcomings: firstly, the absence of any significant account of tumour suppressor genes-a surprising omission given their current interest; secondly, the omission of direct referencing in the text. While this was presumably done deliberately in the interest of readability, it will be frustrating to many readers to have to guess at the relationship between 'Further reading' references and statements in the text. This is particularly annoying in relation to tables. Overall, though, the book is good value and should appeal to a wide audience interested in modern cancer research.

DAVID WYNFORD-THOMAS

Developmental and Genetic Disorders of the Central Nervous System

The 23rd Annual March of Dimes Clinical Genetics Conference on Developmental and Genetic Disorders of the Central Nervous System will be held on 7 to 10 July 1991 at the University of British Columbia, Faculty of Medicine, Vancouver, BC, Canada. Basic and clinical scientists will provide a comprehensive overview of the advances made by molecular, cellular, developmental, cytogenetic, biochemical, and clinical genetic approaches to understanding normal and abnormal central nervous system development and function. The programme includes plenary sessions, optional primer session, ethics and counselling panel, and diagnostic dilemmas session. For informational brochure, contact Professional Services Department, March of Dimes Birth Defects Foundation, 1275 Mamaroneck Avenue, White Plains, NY 10605, USA. Tel: (914) 428-7100. 